\title{
Comparison of Aerosol Delivery by Face Mask and Tracheostomy Collar
}

\author{
Alaa A Bugis MSRCL MSc, Meryl M Sheard MSc RPFT, James B Fink PhD RRT FAARC, \\ Robert J Harwood MSA RRT-NPS FAARC, and Arzu Ari PhD RRT PT CPFT FAARC
}

\begin{abstract}
BACKGROUND: The purpose of this study was to compare the performance of a tracheostomy collar, Wright mask, and aerosol mask attached to a jet nebulizer in facilitating aerosolized medication delivery to the lungs. We also compared albuterol delivery with open versus closed fenestration and determined the effect of inspiratory-expiratory ratio (I:E) on aerosol delivery. METHODS: Albuterol $(2.5 \mathrm{mg} / 3 \mathrm{~mL})$ was administered to an in vitro model consisting of an adult teaching mannequin extrathoracic and upper airway with stoma intubated with an 8-mm fenestrated tracheostomy tube. The cuff was deflated. A collecting filter at the level of the bronchi was connected to a breathing simulator at a tidal volume of $400 \mathrm{~mL}$, breathing frequency of 20 breaths/min, and I:E of $2: 1$ and 1:2. A jet nebulizer was operated with $\mathrm{O}_{2}$ at $8 \mathrm{~L} / \mathrm{min}$. Each interface was tested in triplicate. The flow was discontinued at the end of nebulization. For each test, the nebulizer was attached to a tracheostomy collar with the fenestration open or closed, a Wright mask, or an aerosol mask. Drug was analyzed by spectrophotometry $(276 \mathrm{~nm})$. A paired $t$ test and analysis of variance were performed $(P<.05)$. RESULTS: The mean \pm SD percent albuterol dose delivered distal to the bronchi was greater with the tracheostomy collar with a closed fenestration $(9.4 \pm 1.5 \%)$ compared with an open fenestration $(7.0 \pm 0.8 \%)$. The doses delivered with the Wright mask $(4.1 \pm 0.6 \%)$ and aerosol mask $(3.5 \pm 0.04 \%)$ were both less than with the tracheostomy collar under either condition $(P<.05)$. Increasing the I:E from 1:2 to 2:1 increased aerosol delivery by 2.5-4\%, with significance for the tracheostomy collar with an open fenestration (11.6 $\pm 1.4 \%$ ), Wright mask (7.2 $\pm 0.6 \%)$, and aerosol mask $(6.1 \pm 0.5 \%)$. CONCLUSIONS: In an adult tracheostomy model, the tracheostomy collar delivered more aerosol to the bronchi than the Wright or aerosol mask. An I:E of 2:1 caused greater aerosol deposition compared with an I:E of 1:2. During aerosol administration via a tracheostomy collar, closing the fenestration improved aerosol delivery. Key words: aerosols; fenestration; I:E ratio; mask; nebulizers; respiratory drug administration; tracheostomy. [Respir Care 2015;60(9):1220-1226. (C) 2015 Daedalus Enterprises]
\end{abstract}

\section{Introduction}

In the United States, 16,000,000 people have COPD, with 120,000 deaths annually, making it the fourth highest cause of death. ${ }^{1}$ Many patients with COPD experience acute or chronic respiratory failure and may require prolonged respiratory care and mechanical ventilation through endotracheal or tracheostomy tubes. ${ }^{2}$ Although the most common indication for tracheostomy is upper-airway ob-

\footnotetext{
Ms Bugis is affiliated with the Division of Respiratory Care, King Saud bin Abdulaziz University for Health Sciences, Riyadh, Saudi Arabia. Ms Sheard and Drs Fink, Harwood, and Ari are affiliated with the Division of Respiratory Therapy, Georgia State University, Atlanta, Georgia. Dr Fink is also affiliated with James B Fink, LLC, San Mateo, California.
}

Ms Bugis presented a version of this paper at the OPEN FORUM of the AARC Congress 2011, held November 5-8, 2011, in Tampa, Florida.

\footnotetext{
This study was supported in part by the Saudi Arabian Cultural Mission, Ministry of Higher Education, Washington DC. Dr Fink has disclosed relationships with Aerogen, Dance Biopharm, Parion, Bayer, and Aridis Pharmaceuticals. The other authors have disclosed no conflicts of interest.
}

DOI: $10.4187 /$ respcare.03449 
struction, ${ }^{3}$ this procedure is usually suggested if intubation is planned to last longer than several weeks. ${ }^{2}$ In contrast to endotracheal tubes, tracheostomy tubes are shorter, have a removable inner cannula for cleaning, and may have an open fenestration that can allow breathing through the upper airway or a closed fenestration to provide secure mechanical ventilatory support. ${ }^{4}$ It has been speculated that the use of tracheostomies reduces dead space $^{2}$ and airway resistance and improves secretion clearance. ${ }^{5}$

\section{See the Related Editorial on Page 1365}

Patients with COPD are commonly treated with shortacting bronchodilators and anticholinergic drugs via a nebulizer. A gas-powered jet nebulizer is often used to deliver aerosolized medications. The aerosol reaches patients' airways through a mouthpiece or an aerosol mask, and no significant difference in clinical response has been found between both interfaces. ${ }^{6}$ Piccuito and Hess ${ }^{7}$ reported that albuterol aerosol delivery at high gas flow was inefficient. They concluded that the use of a T-piece resulted in greater albuterol delivery compared with a tracheostomy collar $(P=.001)$. The most efficient nebulizer technique was with the T-piece using no additional flow $(P<.001)$. More recently, Ari et $\mathrm{al}^{8}$ reported greater deposition of albuterol through a tracheostomy tube from a jet nebulizer via a T-piece $(13.9 \pm 2.6 \%)$ versus a tracheostomy collar $(6.9 \pm 0.8 \%, P<.05)$. Moreover, aerosol therapy can be easily delivered through a tracheostomy tube, but is affected by humidification, gas flow, and type of interface used during aerosol therapy. ${ }^{1,7}$ According to a study by Lin et $\mathrm{al}^{9}$ the face mask design affected the inhaled mass delivered. They found that when the mask was separated farther from the face, the inhaled mass was significantly reduced. 9

No studies were found on aerosol delivery with a tracheostomy collar or Wright mask or comparing those devices with an aerosol mask. Patients with tracheostomies have 3 options for inhaled aerosols: (1) plugging a tracheostomy tube with an open fenestration to use an aerosol mask, (2) a tracheostomy collar or tracheostomy tube with an open or closed fenestration, or (3) combination of aerosol mask and tracheostomy collar with an open fenestration such as with the Wright mask.

The Wright mask was recently developed and combines an aerosol mask to cover the nose and mouth with a tracheostomy collar for delivery of humidification with bland aerosol and oxygen for patients with tracheostomies. Although a literature search revealed no peer-reviewed published reports on Wright mask performance, an abstract by Carvalho et al $^{10}$ evaluated the efficacy and feasibility of the Wright mask for delivery of oxygen and humidity to subjects with tracheostomies. The authors reported no differences in blood oxygen saturation, comfort, ease of use,

\section{QUICK LOOK}

\section{Current knowledge}

Aerosol therapy is a common treatment in patients with chronic respiratory disease. Following tracheostomy, the optimum method for aerosol delivery has not been clearly identified. Choice of interface, breathing pattern, and the presence of humidity may all play a role in the efficiency of aerosol delivery.

\section{What this paper contributes to our knowledge}

A tracheostomy collar was the best device for delivering aerosol therapy compared with Wright and aerosol masks in a model of the respiratory system. An inspiratory-expiratory ratio (I:E) of 2:1 resulted in greater aerosol deposition compared with an I:E of 1:2. Aerosol deposition was improved when the fenestration port was closed while using the tracheostomy collar.

or ease of breathing in subjects who used the Wright mask compared with both the tracheostomy collar and aerosol mask. This suggested comparable delivery of oxygen and humidity by the 3 devices. Because of its unique design combining a tracheostomy collar and aerosol mask, the initial expectation for the Wright mask was that there would be greater deposition, especially compared with the tracheostomy collar and aerosol mask interfaces.

The primary purpose of this study was to quantify the inhaled dose of aerosolized medication deposited distal to the trachea using different interfaces (tracheostomy collar, Wright mask, and aerosol mask) in an adult tracheostomy model and to assess the impact of use of a tracheostomy collar with an uncuffed tracheostomy tube with a closed or open fenestration. Upon review of the literature, 3 research questions arose: (1) What is the impact of different interfaces on albuterol delivery using an uncuffed tracheostomy tube with an open fenestration port? (2) How much albuterol is delivered using a tracheostomy collar when the fenestration port is open or closed? (3) What is the effect of the inspiratory-expiratory ratio (I:E) on aerosol delivery in simulated spontaneously breathing adult models with a tracheostomy?

\section{Methods}

\section{Experimental Setup}

An anatomic teaching mannequin (Medical Plastic Laboratory, Gatesville, Texas) with a tracheostomy opening was adapted so that the mannequin's bronchi were connected via a Y-adapter to a collecting filter (303 Respirgard II, Vital Signs, Englewood, Colorado), which was 
connected through a corrugated tube to a breathing simulator (dual-phase control respirator pump, Harvard Apparatus, Holliston, Massachusetts) (Fig. 1). The breathing simulator with a sinusoidal pattern was set to adult parameters of 20 breaths/min with a tidal volume of $400 \mathrm{~mL}^{7}$ at I:E of $1: 2$ and 2:1.

\section{Tracheostomy Tube}

An 8-mm adult fenestrated tracheostomy tube (Shiley, Mallinckrodt, Boulder, Colorado) was placed into the mannequin's stoma. The cuff was always deflated. All experiments were run at I:E of $1: 2$ and 2:1

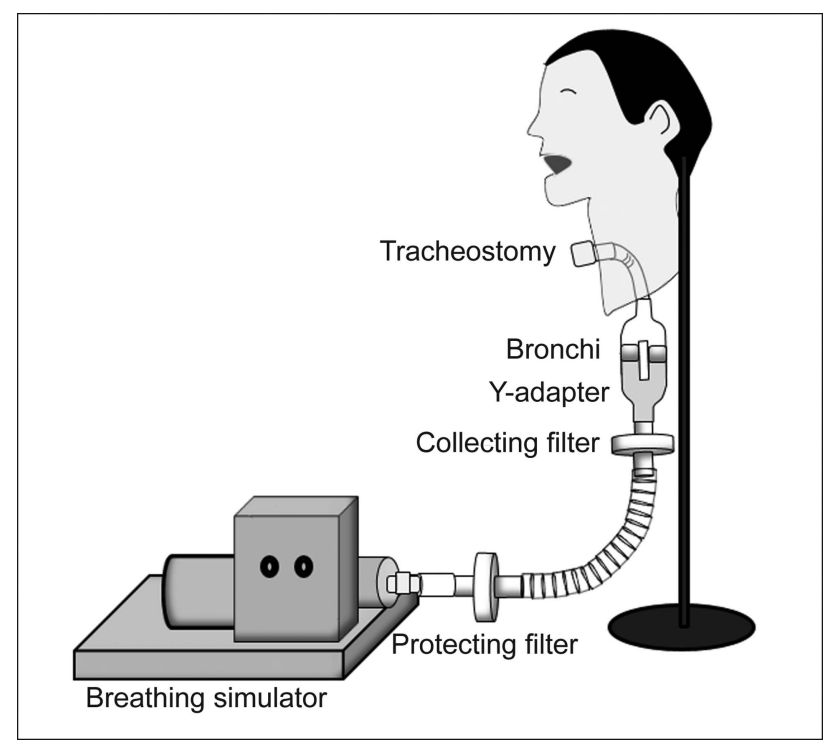

Fig. 1. Experimental setup for the study.

\section{Nebulizer and Flow}

A jet nebulizer (eValueMed, Tri-anim, Sylmar, California) with a reported mass median aerodynamic diameter of $2.3 \mu \mathrm{m}$ and geometric SD of 2.1 was filled with $2.5 \mathrm{mg} /$ $3 \mathrm{~mL}(0.083 \%)$ albuterol sulfate aqueous solution (Dey Pharma, Napa, California). The nebulizer was controlled by a backpressure-compensated flow meter (Soft-Touch Timeter 15001, Allied Healthcare Products, St Louis, Missouri) at $8 \mathrm{~L} / \mathrm{min}$ with $100 \%$ oxygen. At a 1:2 ratio, the inspiratory flow rate was $24 \mathrm{~L} / \mathrm{min}$. At a $2: 1$ ratio, the inspiratory flow rate was $12 \mathrm{~L} / \mathrm{min}$. Flow was discontinued at the end of nebulization.

\section{Interfaces}

Aerosol was delivered from the nebulizer through a tracheostomy collar (Airlife, Cardinal Health, Dublin, Ohio), a Wright mask (Wright Solutions, Marathon, Florida), or a standard aerosol mask (Airlife, Cardinal Health) (Fig. 2). The Wright and aerosol masks were tested with an open fenestration. The tracheostomy collar was tested with open and closed fenestrations.

\section{Assay Technique}

On completion of each experiment, the filters were removed from the experimental setup, labeled, and capped. Drug was eluted with $10 \mathrm{~mL}$ of $0.1 \%$ normal hydrochloric acid with gentle agitation for $3 \mathrm{~min}$. The drug content was quantified using a spectrophotometer (DC 500 series, Beckman Instruments, Fullerton, California) at a wavelength of

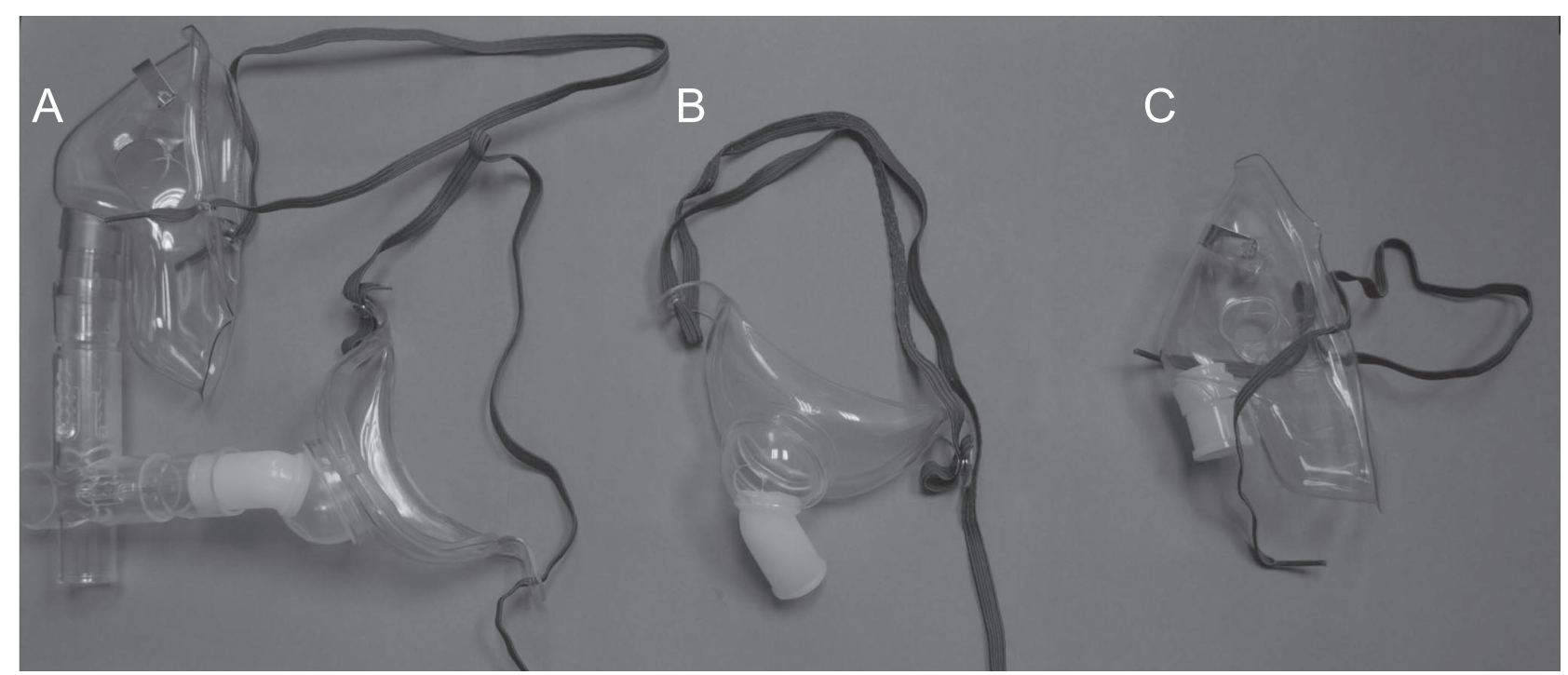

Fig. 2. The different interfaces of the study. A: A Wright mask was tested with an open fenestration. B: A tracheostomy collar was tested with open and closed fenestrations. C: An aerosol mask was tested with an open fenestration. 
Table 1. Percentage of Nominal Dose Delivered to Bronchi in an Adult Tracheostomy Tube Model at I:E 1:2 and 2:1 and Various Interface Combinations

\begin{tabular}{|c|c|c|c|c|}
\hline \multirow[b]{2}{*}{ I:E } & \multicolumn{2}{|c|}{ Tracheostomy Collar (\%) } & \multirow{2}{*}{$\begin{array}{c}\text { Wright Mask } \\
\text { With Open } \\
\text { Fenestration (\%) }\end{array}$} & \multirow{2}{*}{$\begin{array}{c}\text { Aerosol Mask } \\
\text { With Open } \\
\text { Fenestration }(\%)\end{array}$} \\
\hline & $\begin{array}{c}\text { Open } \\
\text { Fenestration }\end{array}$ & $\begin{array}{c}\text { Closed } \\
\text { Fenestration }\end{array}$ & & \\
\hline $1: 2$ & $7.0 \pm 0.8$ & $9.4 \pm 1.5$ & $4.1 \pm 0.6$ & $3.5 \pm 0.04$ \\
\hline $2: 1$ & $11.6 \pm 1.4$ & $12.4 \pm 1.4$ & $7.2 \pm 0.6$ & $6.1 \pm 0.5$ \\
\hline$P$ & .009 & .18 & .02 & .01 \\
\hline
\end{tabular}

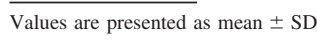

$276 \mathrm{~nm}$ using a $1-\mathrm{mL}$ quartz cuvette. Each interface was tested in triplicate.

\section{Data Analysis}

The amount of aerosol deposited on the filter was quantified and expressed as a percentage of the nominal dose loaded into the nebulizer. Descriptive statistics, including the mean $\pm \mathrm{SD}$, were calculated for each condition tested. Paired $t$ tests were conducted to evaluate differences in the mean inhaled percent of dose delivered by the jet nebulizer at $2 \mathrm{I}$ :E ratios. One-way analysis of variance and the Scheffé post hoc multiple-comparison test were used to determine differences among the means for the conditions tested. Repeated-measures one-way analysis of variance and pairwise comparison were performed to determine differences among the means between open versus closed fenestration. All data analysis was performed using SPSS 18.0 (SPSS, Chicago, Illinois), and statistical significance was defined as $P<.05$. The predictive analytics software PASW 18.0 (SPSS) was used to control data analysis.

\section{Results}

The percent albuterol dose delivered distal to the bronchi of the adult model is shown in Table 1 .

\section{Delivery by Interface}

Delivery of Albuterol was greater with the tracheostomy collar at both I:E of 1:2 and 2:1 $(7.0 \pm 0.80 \%$ and $11.6 \pm 1.4$, respectively) compared with the Wright mask $(4.1 \pm 0.6 \%$ and $7.2 \pm 0.6 \%$, respectively) and aerosol mask ( $3.5 \pm 0.04 \%$ and $6.1 \pm 0.5 \%$, respectively) and the lowest deposition was with the aerosol mask.

\section{Delivery by I:E}

In experiments with an open fenestration, the mean deposition was significantly higher at an I:E of 2:1 versus 1:2
( $P=.009$ for the tracheostomy collar, $P=.02$ for the Wright mask, $P=.01$ for the aerosol mask). The I:E and aerosol delivery were directly related. A longer inspiratory time leads to a greater amount of aerosol deposited. In the closed fenestration experiments, the trend toward higher deposition with an I:E of 2:1 versus 1:2 was not significant $(P=.18)$.

\section{Delivery by Fenestration}

Although deposition trended higher with closed versus open fenestration, differences were not significant $(P>$ $.05)$.

\section{Discussion}

\section{Role of Upper Airways in Aerosol Loss}

We found greater aerosol deposition at the collecting filter when aerosol passed through the tracheostomy tube rather than the simulated upper airway. The upper airways (nose and laryngeal and branching regions) act as an important pulmonary defense mechanism because they provide an extremely efficient aerodynamic filter that prevents larger particle sizes from depositing deeply into the lower airways. ${ }^{11}$ Therefore, nasal and oral breathing imply higher resistance ${ }^{12}$ and greater filtering of aerosol particles as demonstrated with both the Wright and aerosol masks. Aerosol loss in the nasopharynx is higher with a face mask than with a mouthpiece. ${ }^{13}$ Everard et al ${ }^{14}$ found that there was considerable intersubject variation in the ability of the upper airways to filter out particles when inhaled through either the oral or nasal airway. Aerosol loss during transport from upper airways to deep into the lungs is an important factor in nebulizer therapy. ${ }^{15}$ Other factors such as mask seal ${ }^{16}$ and mask efficiency ${ }^{17}$ may play a large role in aerosol delivery. In addition, aerosol generated during exhalation may not reach the lungs at all, whereas large droplets that reach the airway may be deposited in the upper airways such as the naso/oropharynx and hypopharynx. Therefore, only very small droplets may enter the lungs and then be exhaled. ${ }^{13}$ In contrast, Usmani et al ${ }^{18}$ addressed drug particle sizes of albuterol in subjects with obstructive lung disease (asthma), showing clear differences in lung and regional deposition, as well as aerosol losses during exhalation. Although smaller $(1.5 \mu \mathrm{m})$ particles had greater peripheral deposition than either 3.0- or $6.0-\mu \mathrm{m}$ particles, the larger albuterol particles produced greater bronchodilator response.

The volumes of the upper airway also play a role in lung delivery of aerosols. Much of the aerosol entering the upper airway at the end of inspiration is exhaled before reaching the lower airways. A lower upper-airway volume results in a greater proportion of aerosol in the gas volume 
inhaled. The use of a tracheostomy tube bypasses the upper airway, reducing that volume. A review by Epstein ${ }^{4}$ stated that tracheostomy tubes can decrease dead space by up to $100 \mathrm{~mL}$ compared with a spontaneously breathing subject. The internal volume and related anatomic dead space of a 7.5-mm inner diameter tracheostomy tube are between 5 and $6 \mathrm{~mL} .^{2}$ In contrast, one study in cadavers determined the anatomic dead space of the extrathoracic airways (not including the trachea and main bronchi) to be $\sim 75 \mathrm{~mL} .{ }^{19}$ With a tidal volume of $400 \mathrm{~mL}$, the $70 \mathrm{~mL}$ lost in the upper airway would reduce the inhaled dose by a calculated $17.5 \%$. This rationale seems to agree with our findings of reduced lung dose with the Wright and aerosol masks, which require transit through the upper airway.

\section{Effect of Interfaces}

The amount of albuterol delivered distal to the trachea was significantly lower with both the aerosol and Wright masks compared with the tracheostomy collar. This was presumably the result of aerosol wasted in the air and in the upper airways above the stoma. When using the Wright and aerosol masks, aerosol travels through the nose, mouth, and extrathoracic airways, which causes part of the aerosol delivered to be deposited in the upper airways before it reaches the collecting filter, thus reducing the effectiveness of aerosol delivery. Moreover, using a tracheostomy collar caused aerosol particles to travel shorter distances to reach the collecting filter compared with the Wright and aerosol masks.

The results of our study correspond with those of Carvalho et al, ${ }^{10}$ who evaluated the feasibility of the Wright mask and its efficacy with humidity. They concluded that there were no large differences in blood oxygen saturation, comfort, ease of use, or ease of breathing with the Wright mask compared with the tracheostomy collar and aerosol mask.

The results obtained with the tracheostomy collar and a closed fenestration at an I:E of 1:2 (9.4 $\pm 1.5 \%)$ were different from those of Piccuito and Hess ${ }^{7}$ using the same I:E with a tracheostomy collar and non-fenestrated tracheostomy tube $(12.9 \pm 1.3 \%)$. The difference between the results may stem from differences in the experimental models. They used a semicircular model that simulated a patient's neck. Also, the capture filter was attached between the lung model and the distal end of the tracheostomy tube. However, in our study, the mannequin's bronchi were connected via a Y-adapter to a collecting filter. Furthermore, in our study, the cuff was deflated at all times, allowing some aerosol particles to deposit in the upper airways.

\section{Effect of I:E}

Our findings suggest that the I:E substantially impacts the delivered dose. This observation was anticipated with use of continuous output aerosol generators, as aerosol that is not inhaled is typically wasted in the atmosphere. An I:E of 2:1 allows for $33 \%$ more of the generated aerosol to be inhaled compared with an I:E of 1:2. The difference in the deposited amount between these I:E ratios can be explained by the breathing pattern and the respiratory phase in which the medication was delivered. The inspiratory time was longer at an I:E of 2:1 compared with 1:2, allowing more time to inhale the aerosolized drug, thus causing more albuterol delivery to the simulated lung. In all open fenestration experiments, the amount of aerosolized albuterol deposited was affected significantly by the I:E. These findings suggest that a longer inspiratory time and a shorter time between inspirations lead to inhalation of a greater proportion of the emitted dose.

These results corroborate the findings of Hess et al, ${ }^{20}$ who found that a longer inspiratory time increased the amount of albuterol aerosol delivered by a nebulizer $(P<.001)$. Also, our results agree with those of Cameron et $\mathrm{al}^{21}$ who reported that lung deposition of a released aerosol was decreased markedly by reducing aerosol residence time (I:E). The results of our study may be in contrast to those of Lim et al, ${ }^{22}$ who found that increasing the I:E by adding a breath-hold improved gas exchange during partial liquid ventilation. Oxygenation during partial liquid ventilation was affected by the I:E to a greater extent than during gas ventilation. Moreover, Gottschalk et $\mathrm{al}^{23}$ found that an additional $14-17 \%$ of the aerosol dose in the lungs was associated with deep inhalation and breathholding. However, these researchers evaluated the impact of breath-holding a bolus of aerosol, so the results show improvements with a single breath. In the case of continuous aerosol generation, a longer breath-hold leads to a greater proportion of emitted aerosol lost to the atmosphere that cannot be inhaled. The impact of breath-holding cannot be assessed with this model; however, it is less likely that inspiratory pause or breath-hold would increase total lung dose during slow inspiration with shorter times between inspirations.

\section{Effect of Fenestration}

In this study, albuterol delivery using a tracheostomy collar with a closed fenestration was greater compared with an open fenestration. The difference in the deposited amount between open and closed fenestrations may be explained by the dilution of air being drawn through the open fenestration from the upper airway. This means that less of the 400-mL tidal volume was drawn from the aerosol interface, so a smaller proportion of inhaled gas contained aerosol. In contrast, with a closed fenestration, the only source of inhaled gas was from the tracheostomy, and a higher proportion of the inhaled gas contained aerosol. 
We had anticipated that the open fenestration would allow a more direct path of inhaled aerosol from the upper airways to the lungs and that the closed fenestration would make the tracheostomy tube an obstruction to inhaled aerosol by the mouth or nose. However, that variable was beyond the scope of this evaluation.

\section{Clinical Implications}

Based on this study, 3 insights may be given to clinicians to achieve a better outcome when administering aerosolized medications. First, a tracheostomy collar delivers more aerosol than either the aerosol or Wright mask, even when there is no open fenestration. Second, when delivering aerosol via a tracheostomy collar, close the fenestration hole during aerosol administration. Third, be aware that I:E impacts aerosol delivery, and instructing the patient to inhale the aerosolized medication slowly with a shorter expiratory time between inspirations may increase the delivered dose.

\section{Limitations}

This experiment was an in vitro bench study; therefore, the results should be subjected to clinical validation. Different breathing patterns may be seen in vivo. In addition, a homogeneous breathing simulator was used. Human subjects would show heterogeneous breathing patterns and different lung conditions. We did not study the effect of different breathing patterns, and the parameters were the same in all experiments. This study was conducted with only one type and size of tracheostomy tube. It is also important to note that the Wright mask was manufactured for humidification therapy via the nose, mouth, and trachea, not for aerosol drug therapy.

\section{Future Studies}

The effect of changing the respiratory setting should be explored to determine how aerosol delivery would be affected with different patient conditions, diseases, and ventilatory settings. Different I:E ratios should be explored further to help patients relieve their symptoms and to provide guidance to clinicians in administering aerosol therapy. In addition, different types and sizes of tracheostomy tubes should be studied to help other patients with varying equipment, such as pediatric tracheostomy tubes. Finally, clinical studies showing differences in outcome are required to fully vet the implications of this bench study.

\section{Conclusions}

This study demonstrated that a tracheostomy collar is the best device for delivering aerosol therapy compared with
Wright and aerosol masks. An I:E of 2:1 lead to greater albuterol delivery compared with an I:E of 1:2. Albuterol delivery was better when the fenestration port was closed compared with open while using the tracheostomy collar.

\section{ACKNOWLEDGMENTS}

We thank Georgia State University for allowing us to carry out this research in the respiratory care labs; we especially thank Lynda T Goodfellow EdD RRT FAARC for her advice in the early phase of this study. We also thank Thomas A Barnes EdD RRT FAARC (Respiratory Care Leadership Master Program, Northeastern University, Boston, Massachusetts) for his insightful support.

\section{REFERENCES}

1. Johnson DC. Interfaces to connect the HandiHaler and Aerolizer powder inhalers to a tracheostomy tube. Respir Care 2007;52(2):166-170.

2. Pierson DJ. Tracheostomy and weaning. Respir Care 2005;50(4): 526-533.

3. Adoga AA, Ma'an ND. Indications and outcome of pediatric tracheostomy: results from a Nigerian tertiary hospital. BMC Surgery 2010; 10(1):2.

4. Epstein SK. Anatomy and physiology of tracheostomy. Respir Care 2005;50(4):476-482.

5. Durbin CG Jr, Perkins MP, Moores LK. Should tracheostomy be performed as early as 72 hours in patients requiring prolonged mechanical ventilation? Respir Care 2010;55(1):76-87.

6. Hess DR. Nebulizers: principles and performance. Respir Care 2000; 45(6):609-622.

7. Piccuito CM, Hess DR. Albuterol delivery via tracheostomy tube. Respir Care 2005;50(8):1071-1076.

8. Ari A, Harwood RJ, Sheard MM, Fink JB. An in vitro evaluation of aerosol delivery through tracheostomy and endotracheal tubes using different interfaces. Respir Care 2012;57(7):1066-1070.

9. Lin HL, Restrepo RD, Gardenhire DS, Rau JL. Effect of face mask design on inhaled mass of nebulized albuterol, using a pediatric breathing model. Respir Care 2007;52(8):1021-1026.

10. Carvalho E, Crescimone N, Fernandez C, Giquel J, Franzmann E, Candiotti K. Wright humidification mask in chronic tracheostomy patients (abstract). Primary Care Respir J 2010;19(2):A21.

11. Newhouse MT, Ruffin RE. Deposition and fate of aerosolized drugs. Chest 1978;73(6):936-943.

12. Becquemin MH, Swift DL, Bouchikhi A, Roy M, Teillac A. Particle deposition and resistance in the noses of adults and children. Eur Respir J 1991;4(6):694-702.

13. Newman SP. Aerosol deposition considerations in inhalation therapy. Chest 1985;88(Suppl 2):152S-160S.

14. Everard ML, Hardy JG, Milner AD. Comparison of nebulised aerosol deposition in the lungs of healthy adults following oral and nasal inhalation. Thorax 1993;48(10):1045-1046.

15. Ferron GA. Aerosol properties and lung deposition. Eur Respir J 1994;7(8):1392-1394.

16. Schüepp KG, Jauernig J, Janssens HM, Tiddens HA, Straub DA, Stangl $\mathrm{R}$, et al. In vitro determination of the optimal particle size for nebulized aerosol delivery to infants. J Aerosol Med 2005;18(2):225-235.

17. Wildhaber JH, Dore ND, Wilson JM, Devadason SG, LeSouëf PN. Inhalation therapy in asthma: nebulizer or pressurized metered-dose inhaler with holding chamber? In vivo comparison of lung deposition in children. J Pediatr 1999;135(1):28-33.

18. Usmani OS, Biddiscombe MF, Barnes PJ. Regional lung deposition and bronchodilator response as a function of $\beta_{2}$-agonist particle size. Am J Respir Crit Care Med 2005;172(12):1497-1504. 
19. Nunn JF, Campbell EJ, Peckett BW. Anatomical subdivisions of the volume of respiratory dead space and effect of position of the jaw. J Appl Physiol 1959;14(2):174-176.

20. Hess DR, Dillman C, Kacmarek RM. In vitro evaluation of aerosol bronchodilator delivery during mechanical ventilation: pressure-control vs. volume control ventilation. Intensive Care Med 2003;29(7): 1145-1150.
21. Cameron D, Arnot R, Clay M, Silverman M. Aerosol delivery in neonatal ventilator circuits: arabbitlung model.PediatrPulmonol 1991;10(3):208-213.

22. Lim CM, Koh Y, Shim TS, Lee SD, Kim WS, Kim DS, Kim WD. The effect of varying inspiratory to expiratory ratio on gas exchange in partial liquid ventilation. Chest 1999;116(4):1032-1038.

23. Gottschalk B, Leupold W, Woller P. Deposition of aerosols in the airways. J Respir Dis 1978;152(2):139-146.

This article is approved for Continuing Respiratory Care Education credit. For information and to obtain your CRCE

(free to AARC members) visit 